\title{
Evaluation of Substance Abuse Cases Admitted in ICU of Poison Control Center- Ain Shams University Hospitals by Certain Clinical Scoring Systems
}

\author{
Raghda Essam Eldin, Hoda Salah Othman, Hoda M Salah Eldin', \\ ${ }^{1}$ Department of Forensic Medicine \& Clinical Toxicology, Faculty of Medicine, Ain Shams University, Cairo, Egypt.
}

\begin{abstract}
Objectives: Admissions to the intensive care unit (ICU) related to abuse of alcohol and illicit drugs have been shown to be both common and costly. The current study aimed at evaluation of clinical characteristics of drug abuse and utility of APACHE II score and Sequential Organ Failure Assessment (SOFA) score as predictors of severity and outcome. Method: crosssectional hospital-based observational study carried out on drug abuse related ICU admissions, in the period from first of July 2018 till December 31st, 2018 were enrolled in this study. Clinical data and laboratory variables were assessed on day1, day 2, day4, day 6 and endpoint. Clinical data were employed in the calculation of APACHE II and SOFA scores. Results: A total of 87 substance abuse related ICU admissions were enrolled. Cases were subdivided into group I (tramadol or/and opioids), group II (cannabis or synthetic cannabinoids) and group III (ethanol ingestion complicated by methanol toxicity) representing 67.87\%, 18.39\% and 13.79\% respectively. Drugs affecting CNS were co-ingested in $34.48 \%$. Clinical findings showed statistically significant difference in relation to type of abused substance. Both APACHE II and SOFA scores differ significantly in the three groups. Short ICU stay was noted in the majority of cases (77\%). Overall, in-hospital mortality and morbidity were $11.49 \%$ and $10.34 \%$ respectively. Morbidity was higher among longer ICU stay while mortality was recorded mostly during the first 24 hours. Conclusion: APACHE II and SOFA scores can be used to determine severity in ICU patients with substance abuse, and SOFA score can point to the organ failure development.
\end{abstract}

Key words Substance abuse-ICU-APACHE II score-SOFA score

\section{Introduction}

$\mathrm{S}$ ubstance abuse continues to be a large public health concern worldwide. The availability of more potent drugs, the increasing number of substances and their potential combinations poses a greater challenge to prevention and treatment of drug use disorders (World Drug Report, 2020).

Although drug overdose-related deaths attract much public attention, there are substantial consequences of nonfatal overdoses including cardiac and musculoskeletal problems, aspiration pneumonia, cognitive impairment and hypoxic brain injury, renal dysfunction, and physical injuries sustained during the intoxication event. Increased ED visits, hospitalization rates and total intensive care unit (ICU) admissions lead to a substantial increase in health care costs of substance abuse cases (Martins et al, 2015).

Classical recreational drugs such as heroin, cocaine, cannabis, ethyl alcohol, and benzodiazepines remain the most common substances associated with acute drug intoxication requiring emergency medical attention Over the past decade, new psychoactive substances (NPS) have emerged and have become increasingly popular leading to an increase in synthetic cannabinoids-related adverse events and ED visits (Lamy et al., 2017; Orsini et al, 2017).
Compared to the global incidence, a higher incidence of substance abuse in Egypt especially in Great Cairo was reported by the national research for addiction from 2007 through 2014 (Sabry et al., 2015). The current study was conducted in Poison Control Center of Ain Shams University hospitals (PCC-AUH) aiming at determining trends of drug abuse among cases presented to PCC-ASUH in a six-month duration from 1st of July till end of December 2018, in addition to evaluation of clinical characteristics of substance abuse cases admitted in the ICU of PCC-ASUH by using APACHE II score and SOFA score as predictors of severity and outcome.

\section{Subjects and Methods}

This work was planned as cross-sectional hospital-based observational study.

Subjects: Patients, of both sexes, with substance abuse who were admitted in the ICU of PCC-ASU in the period from first of July 2018 till December 31st, 2018 were enrolled in this study. Diagnosis of substance abuse was based on history, clinical picture and/or laboratory investigations. Treatment was provided for all patients following the policy of management protocols of the PCC-ASU. Based on the possibility of alteration in the levels of the measured biomarkers, the following patients were excluded: 
patients less than 18 years and more than 65 years, pregnant females, patients transferred from another ICU history of renal or hepatic failure (Sekulic et al, 2015).

Ethical Considerations: Data were collected after approval of the Research Ethics Committee of Faculty of Medicine Ain Shams University. Also, an approval was obtained from the general director of the PCC -ASUH. An informed consent was obtained from the patients or their relatives (next of kin). All data were stored anonymously, with consideration of confidentiality issues. The collected data was used only for the purpose of the study.

Recorded data were tabulated and statistically analysed using standard SPSS (Standard Package for Social Science) software package, version 20 (Chicago. IL).

Data:

Type of abused substance was recorded, and patients were sub-classified accordingly into 3 groups:

- Group I: including patients abusing either tramadol or opioids.

- Group II: including patients abusing cannabis or synthetic cannabinoids.

- Group III: including patients with ethanol ingestion complicated by methanol toxicity.

Recorded data in the present study included: age, gender, other co-ingested CNS drugs, outcome including recovery, mortality, complications developing during hospital stay and length of ICU stay.

Clinical and laboratory variables were recorded on 1 st 24 hours, repeated after 24 hours from the initial assessment, on day 4 days, on day 6 and lastly at the time of patient's discharge, referral, or death.

Investigations: were performed according to specific requirements of each patient following the guidelines of the PCC -ASU management protocols. General laboratory investigations included random blood sugar, serum sodium and potassium, serum urea and creatinine, serum ALT and AST, serum bilirubin, complete blood picture, and arterial blood gases. Additionally, Urine sample had been used to detect Cannabis, opiates and tramadol using automated immunoassay Roche/Hitachi cobas C311 (Taskinen et al, 2017). Quantitative determination of alcohol was performed according to Sunshine et al, (1961).

Variables of different days of the study were employed in the calculation of two scores (Rapsang and Shyam, 2014):

1. Acute Physiology and Chronic Health Evaluation II (APACHE II) score was calculated during the 1st 24 hours after admission using the worst measured values. An integer score from 0 to 71 was computed based on several measurements where higher scores denoted more severity and a higher risk of death.

2. Sequential Organ Failure Assessment (SOFA) score was calculated based on the degree of dysfunction of six organ systems: respiratory, cardiovascular, renal, hepatic, hematological and neurological systems. SOFA score was calculated at the time of each sample collection.

\section{Results}

A total of 87 ICU admitted cases with substance abuse were enrolled in this study. Group I ( tramadol or/and opioids cases) represented $67.87 \%$ of total cases(n=59),followed by group II( cannabis or synthetic cannabinoids)representing $18.39 \%$ cases $(n=16)$ whereas group III(ethanol ingestion complicated by methanol toxicity) included 12 cases (13.79\%). In $34.48 \%$ of cases, drugs affecting CNS were co-ingested including pregabalin (4.6\%), second generation antipsychotics (9.2\%), benzodiazepines (8.05\%) other sedatives (3.45\%), tricyclic antidepressants (1.14\%), trihexyphenidyl (Parkinol $\left.{ }^{\circledR}\right)$ (1.14\%), fenethylline (Captagon $\left.{ }^{\circledR}\right)$ (1.14) and poly drug use in $5.74 \%$.

Age of all cases ranged from 20 to 65 years with mean of $34 \pm 9.617$ years. Males constituted the majority of cases (95\%) with only 4 female cases all among group I cases.

Clinical Evaluation: The majority of cases (83.91\%) suffered disturbed level of consciousness. Coma grade II was observed in $42 \%$ of patients followed by irritable coma (20\%), coma grade IV $(9.2 \%)$ while grade I and grade III coma were similarly observed in 5.75\%. Mechanical ventilation was required for $39 \%$ of patients. Acidosis predominated the recorded abnormal ABG findings whether respiratory $(42.5 \%)$, metabolic $(16.09 \%)$ or mixed (2.3\%). CVS and GIT manifestations were less commonly recorded (24 and $14.94 \%$ respectively) (table 1).

By analysis of clinical findings in relation to type of abused substance, statistically significant difference was found (table 1). Disturbed level of consciousness was present in almost all group I cases (96.61\%) mainly as grade II coma (45.76 \%) and irritable coma (25.42\%). Additionally, mechanical ventilation was required in almost half of cases in this group $(47.6 \%)$. Respiratory acidosis was also recorded in $57.63 \%$. However, shock on admission was presented mostly among group III (41.67\%) followed by group I (11.86).

Regarding group II, disturbed level of consciousness was also present in $68.75 \%$ of cases mainly as grade II coma (43.7\%) and irritable coma (18.75\%). However, mechanical ventilation was less needed (12.5\% of cases). Abnormal ABG were also less noted among this group but conversely, both CVS manifestations other than shock and GIT symptoms were highest (37.5\%).

A lower incidence of disturbed level of consciousness among group III cases (41.6\%) was recorded and mechanical ventilation was required in third of them. Among group III cases, metabolic acidosis was detectable in all. Additionally, shock on admission and GIT symptoms were also pronounced.

Scoring systems: Mean APACHE II and SOFA score values in all studied patients are displayed in table (2). Highest mean APACHE II score values were noted in group I (13.796 \pm 5.948) followed by Group III, however highest mean SOFA score values were recorded among group II cases (3.333 \pm 3.215$)$. Whilst 
no significant difference was found between group I and III regarding both APACHE II and SOFA scores (table 2c), significant difference was found on comparing both group I (table 2a) and III to group II (table 2b).

Length of ICU stay /Outcome: By the end of the study, short ICU stay (one day or less) was noted in the majority of cases (77\%) and recovery was recorded in more than half of studied cases (56.32\%). Overall, inhospital mortality and morbidity were $11.49 \%$ and $10.34 \%$ respectively. Statistically significant difference was found as regards the recorded outcome in relation to the duration of ICU stay (table 3); while morbidity was higher among those who stayed more than one day in ICU, mortality was recorded mostly during the first 24 hours. Unknown outcome was noted in $21.84 \%$ of cases due to discharge against medical advice.

Although the outcome did not show a statistically significant difference between the three studied, however there was no recorded mortality in group II and high morbidity and mortality were observed in group III (both 25\%). On the other hand, short ICU stay was significantly noted among group I and group II (83.05 \% and $81.25 \%$ respectively) while longer stay was linked to group III(table 4).

Table (1): Chi Square Statistical Analysis of clinical manifestations among studied groups

\begin{tabular}{|c|c|c|c|c|c|c|c|c|c|c|c|}
\hline & \multicolumn{8}{|c|}{ Groups } & \multirow{2}{*}{\multicolumn{2}{|c|}{ Chi-Square }} \\
\hline & & \multicolumn{2}{|c|}{ Group I } & \multicolumn{2}{|c|}{ Group II } & \multicolumn{2}{|c|}{ Group III } & \multicolumn{2}{|c|}{ Total } & & \\
\hline & & $\mathbf{N}$ & $\%$ & $\mathbf{N}$ & $\%$ & $\mathbf{N}$ & $\%$ & $\mathbf{N}$ & $\%$ & $X^{2}$ & P-value \\
\hline \multirow{6}{*}{ 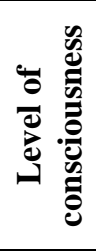 } & Conscious & 2 & 3.39 & 5 & 31.25 & 7 & 58.33 & 14 & 6.09 & \multirow{6}{*}{30.177} & \multirow{6}{*}{$0.001^{*}$} \\
\hline & Coma I & 3 & 5.08 & 1 & 6.25 & 1 & 8.33 & 5 & 5.75 & & \\
\hline & Coma II» & 27 & 45.76 & 7 & 43.75 & 3 & 25 & 37 & 42.53 & & \\
\hline & Coma III & 5 & 8.47 & 0 & 0 & 0 & 0 & 5 & 5.75 & & \\
\hline & Coma IV & 7 & 11.86 & 0 & 0 & 1 & 8.33 & 8 & 9.20 & & \\
\hline & Irritable coma & 15 & 25.42 & 3 & 18.75 & 0 & 0 & 18 & 20.69 & & \\
\hline \multirow{2}{*}{ 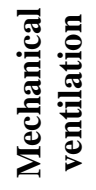 } & Not ventilated & 31 & 52.54 & 14 & 87.50 & 8 & 66.67 & 53 & 60.92 & \multirow{2}{*}{6.654} & \multirow{2}{*}{$0.036^{*}$} \\
\hline & Ventilated & 28 & 47.46 & 2 & 12.50 & 4 & 33.33 & 34 & 39.08 & & \\
\hline \multirow{4}{*}{ 象 } & Normal & 22 & 37.29 & 12 & 75.00 & 0 & 0 & 34 & 39.08 & \multirow{4}{*}{82.428} & \multirow{4}{*}{$<0.001^{*}$} \\
\hline & Respiratory acidosis & 34 & 57.63 & 3 & 18.75 & 0 & 0 & 37 & 42.53 & & \\
\hline & Metabolic acidosis & 1 & 1.69 & 1 & 6.25 & 12 & 100 & 14 & 16.09 & & \\
\hline & Mixed acidosis & 2 & 3.39 & 0 & 0 & 0 & 0 & 2 & 2.30 & & \\
\hline \multirow{3}{*}{$\sum_{0}^{\infty}$} & No clinical finding & 50 & 84.75 & 9 & 56.25 & 7 & 58.33 & 66 & 75.86 & \multirow{3}{*}{26.036} & \multirow{3}{*}{$<0.001^{*}$} \\
\hline & Shock & 7 & 11.86 & 1 & 6.25 & 5 & 41.67 & 13 & 14.94 & & \\
\hline & $\begin{array}{c}\text { Other CVS } \\
\text { manifestations** }\end{array}$ & 2 & 3.39 & 6 & 37.50 & 0 & 0 & 8 & 9.20 & & \\
\hline \multirow{3}{*}{ 㥀 } & No clinical finding & 57 & 96.61 & 10 & 62.50 & 7 & 58.33 & 74 & 85.06 & \multirow[t]{2}{*}{19.344} & \multirow[t]{2}{*}{$<0.001 *$} \\
\hline & Vomiting & 2 & 3.39 & 6 & 37.50 & 5 & 41.67 & 13 & 14.94 & & \\
\hline & Total & 59 & 100 & 16 & 100 & 12 & 100 & 87 & 100 & & \\
\hline
\end{tabular}

- According to Reed's classification of coma, $N$ : Number of patients, $X^{2}$ : Chi square statistical analysis, $P$-value > $0.05=$ Non -significant, $P$-value $\leq 0.05=$ Significant*, ** other CVS manifestations include: sinus bradycardia, chest pain and heart block

Table (2a): Student "t" Statistical Analysis for comparison between group I and group II cases as regards APACHE II Score and SOFA score values.

\begin{tabular}{|c|c|c|c|c|c|}
\hline \multirow{2}{*}{ Clinical Scores } & \multicolumn{2}{|c|}{ Group I } & \multicolumn{2}{c|}{ Group II } & \multicolumn{2}{c|}{ Test value } \\
\cline { 2 - 5 } & Range & Mean \pm SD & Range & Mean \pm SD & t \\
\hline APACHE II & $4-30$ & $13.796 \pm 5.948$ & $3-23$ & $9.867 \pm 5.755$ & \multirow{2}{*}{13.5} \\
\hline SOFA & $1-8$ & $2.900 \pm 2.283$ & $1-7$ & $3.333 \pm 3.215$ & \\
\hline
\end{tabular}

$S D=$ standard deviation, $P$-value $>0.05=$ Non - significant, $P$-value $\leq 0.05=$ Significant

Table (2b): Student “t”" Statistical Analysis for comparison between group II and group III cases as regards APACHE II Score and SOFA score values.

\begin{tabular}{|c|c|c|c|c|c|}
\hline \multirow{2}{*}{ Clinical Scores } & \multicolumn{2}{|c|}{ Group II } & \multicolumn{2}{c|}{ Group III } & \multicolumn{2}{c|}{ Test value } \\
\cline { 2 - 5 } & Range & Mean \pm SD & Range & Mean \pm SD & t \\
\hline APACHE II & $3-23$ & $9.867 \pm 5.755$ & $1-23$ & $13.091 \pm 7.341$ & \multirow{2}{*}{6.25} \\
\hline SOFA & $1-7$ & $3.333 \pm 3.215$ & $0-5$ & $2.429 \pm 1.813$ & \\
\hline
\end{tabular}

$S D=$ standard deviation, $P$-value $>0.05=$ Non -significant, $P$-value $\leq 0.05=$ Significant 
Table (2c): Student "t" Statistical Analysis for comparison between group I and group III cases as regards APACHE II Score and SOFA score values.

\begin{tabular}{|c|c|c|c|c|c|}
\hline \multirow{2}{*}{ Clinical Scores } & \multicolumn{2}{|c|}{ Group I } & \multicolumn{2}{c|}{ Group III } & Test value \\
\cline { 2 - 5 } & Range & Mean \pm SD & Range & Mean \pm SD & t \\
\hline APACHE II & $4-30$ & $13.796 \pm 5.948$ & $1-23$ & $13.091 \pm 7.341$ & \multirow{2}{*}{0.63} \\
\hline SOFA & $1-8$ & $2.900 \pm 2.283$ & $0-5$ & $2.429 \pm 1.813$ & \\
\hline
\end{tabular}

$S D=$ standard deviation, $P$-value $>0.05=$ Non -significant, $P$-value $\leq 0.05=$ Significant

Table (3): Chi Square Statistical Analysis of the outcome and duration of ICU stay in all Studied Patients.

\begin{tabular}{|c|c|c|c|c|c|c|c|c|}
\hline \multirow{3}{*}{ Outcome } & \multicolumn{6}{|c|}{ Duration ICU } & \multirow{2}{*}{\multicolumn{2}{|c|}{ Chi-Square }} \\
\hline & \multicolumn{2}{|c|}{ One day or Less } & \multicolumn{2}{|c|}{ More than one day } & \multicolumn{2}{|c|}{ Total } & & \\
\hline & $\mathbf{N}$ & $\%$ & $\mathbf{N}$ & $\%$ & $\mathbf{N}$ & $\%$ & $X^{2}$ & P-value \\
\hline Unknown〉 & 18 & 26.87 & 1 & 5.00 & 19 & 21.84 & \multirow{5}{*}{19.501} & \multirow{5}{*}{$<0.001^{*}$} \\
\hline Mortality & 7 & 10.45 & 3 & 15.00 & 10 & 11.49 & & \\
\hline Recovery & 40 & 59.70 & 9 & 45.00 & 49 & 56.32 & & \\
\hline Morbidity & 2 & 2.99 & 7 & 35.00 & 9 & 10.34 & & \\
\hline Total & 67 & 100.00 & 20 & 100.00 & 87 & 100.00 & & \\
\hline
\end{tabular}

$\downarrow$ Unknown outcome: includes patients who left against medical advice, $N$ : Number of patients, $X^{2}$ : Chi square statistical analysis, $P$-value $>0.05=$ Non -significant, $P$-value $\leq 0.05=$ Significant $*$

Table (4): Chi Square Statistical Analysis showing comparison of outcome and ICU duration in the three studied groups.

\begin{tabular}{|c|c|c|c|c|c|c|c|c|c|c|c|}
\hline & & \multicolumn{8}{|c|}{ Groups } & \multirow{2}{*}{\multicolumn{2}{|c|}{ Chi-Square }} \\
\hline & & \multicolumn{2}{|c|}{ Group I } & \multicolumn{2}{|c|}{ Group II } & \multicolumn{2}{|c|}{ Group III } & \multicolumn{2}{|c|}{ Total } & & \\
\hline & & $\mathbf{N}$ & $\%$ & $\mathbf{N}$ & $\%$ & $\mathbf{N}$ & $\%$ & $\mathbf{N}$ & $\%$ & $\mathbf{X}^{2}$ & P-value \\
\hline \multirow{4}{*}{ 葛 } & Unknown & 13 & 22.03 & 4 & 25 & 2 & 16.67 & 19 & 21.84 & \multirow{4}{*}{8.504} & \multirow{4}{*}{0.203} \\
\hline & Mortality & 7 & 11.86 & 0 & 0 & 3 & 25 & 10 & 11.49 & & \\
\hline & Recovery & 34 & 57.63 & 11 & 68.75 & 4 & 33.33 & 49 & 56.32 & & \\
\hline & Morbidity & 5 & 8.47 & 1 & 6.25 & 3 & 25 & 9 & 10.34 & & \\
\hline \multirow{2}{*}{ 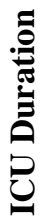 } & One day or less & 49 & 83.05 & 13 & 81.25 & 5 & 41.67 & 67 & 77.01 & \multirow{2}{*}{13.96} & \multirow{2}{*}{$0.007 *$} \\
\hline & More than one day & 10 & 16.95 & 3 & 18.75 & 7 & 58.33 & 20 & 22.99 & & \\
\hline & Total & 59 & 100 & 16 & 100 & 12 & 100 & 87 & 100 & & \\
\hline
\end{tabular}

N: Number of patients, $X^{2}$ : Chi square statistical analysis, $P$-value $>0.05=$ Non -significant, $P$-value $\leq 0.05=$ Significant*

\section{Discussion}

In the current study substance abuse-associated overdose admissions to the ICU were mainly related to tramadol or/and opioids followed by cannabis or synthetic cannabinoids. This can bring to mind the high prevalence of opioid abuse in the Egyptian community and the alarming studies estimating that tramadol users have exceeded $40 \%$ of the total Egyptian drug users, being the first illicit drug of abuse followed by cannabis Egyptian anti-addiction hotline statistics (Bassiony et al., 2018).

Given its dual properties of being an opioid while having serotonergic and noradrenergic effects, a number of studies have shown that several reasons contributed to the popularity of tramadol including: energy and mood boosting; alleged improvement of sexual performance; perception that its effects last long; and as self-medication for pain relief or the relief of symptoms of depression, anxiety or other comorbid psychiatric disorders(General Secretariat of Mental Health and Addiction, 2017; Abou El Magd et al.,2018)

The observed substantial need for critical care in opioid overdose can be attributed to the consequential effects of acute opioid intoxication and overdose including respiratory depression, aspiration pneumonia, acute lung injury, multisystem organ damage, rhabdomyolysis, anoxic brain injury and cardiac arrest that warrant management in the intensive care unit (Stevens et al., 2017).

Cannabinoids were less represented in the current study although cannabis continues to be the most widely used drug (World Drug Report, 2019): a fact that could be justified by the relatively mild effects 
of smoked or ingested phytocannabinoids uncommonly presented to ER or requiring ICU admission. On the other hand, less reported use of SCs may be related to $1^{\text {st }}$ :the growing recognition of the associated severe adverse health events which may necessitate aggressive supportive care (Helander et al., 2014) $2^{\text {nd }}$ : users of cannabis have reported that they prefer natural cannabis to synthetic cannabinoids(World Drug Report, 2019) $3^{\text {rd }}$ : the addition of some members of this rapidly emerging class of drugs to Schedule No. 1 of the Egyptian Drugs Act thus criminalizing their possession and trafficking.

In the current study, co-ingested drugs affecting CNS were noted in $34.48 \%$ of cases including mainly second-generation antipsychotics, benzodiazepines and pregabalin in addition to polydrug use patterns in $5.74 \%$. Suggested motives for use mainly relate to: self-medication of anxiety, sleep disturbance, insomnia and depression; attenuation of negative effects of use or withdrawal from other substances; and enhancement of pleasurable effects (McLarnon et al, 2011; Malekshahi et al., 2015; World Drug Report, 2019).

The prevalence of male cases in this study is consistent with global reports, however the stigma faced by women who use drugs in addition to the encountered social, cultural, and personal barriers in accessing treatment for drug use disorders may misjudge the extent of drug use among women (Mohamed et al., 2015; World Drug Report,2018).

It was not surprising that the majority of cases presented with disturbed level of consciousness especially among tramadol/opioid abusers. Opioidinduced sedation is produced directly through agonist effects at $\mu$-opioid receptors in addition to reduced arousal by inhibition of pontine cholinergic neurons. In overdose situations, diffuse cortical dysfunction may also occur due to confounding factors including hypoxia, hypothermia, and shock (Montandon and Horner, 2019; Kerrigan and Goldberger, 2020).

On the other hand, reported agitation in the present study in tramadol or/and opioids cases was not unexpected. In patients with acute opioid overdose, seizures most likely are caused by hypoxia, however, they should be anticipated in patients with meperidine, propoxyphene, or tramadol toxicity owing to their nonopioid-receptor effects specially blockade of the presynaptic reuptake of released serotonin (Nakhaee et al., 2019; Nelson and Olsen, 2019).

Disturbed level of consciousness and irritable coma in cannabinoid abusers was commonly recorded in our study and similarly reported by Gugelmann et al., (2014), Takematsu et al., (2014) and Tournebize et al, (2017). Synthetic cannabinoids are potent agonists at the cannabinoid receptors CB1 densely present in the brain and are expressed by presynaptic glutamatergic or GABAergic neurons. Activation of these receptors leads to decreased glutamate or GABA release, which in turn results in reduced excitation or suppressed inhibition, respectively (Armstrong et al., 2019).

Additionally, compared with natural cannabis, the reported severity in SCs may be related to the absence of cannabidiol and cannabinol which have anticonvulsant properties and antagonizes the psychotomimetic and other psychotropic effects of THC (Harris and Brown, 2013). Hurst et al., (2011) reported that synthetic cannabinoid cases commonly involve multiagent exposures including other illicit or prescription drugs or alcohol, which might be responsible for the effects observed.

Thirty-nine percent of patients included in this study underwent mechanical ventilation, either due to acute hypoxemic and/or hypercapnic respiratory failure, decreased level of consciousness with inability to safely protect airways, or cardiac arrest on arrival to emergency department.

As previously outlined in other reports, respiratory depression is particularly pronounced with opioid overdose. $\mu 2$ receptors are implicated in the respiratory depressant effects of opioid agonists by the combination of diminished sensitivity of the medullary chemoreceptors to hypercapnia and depression of the ventilatory response to hypoxia (Mowry et al, 2016). SCs were also linked to respiratory dysfunction. The proposed mechanisms responsible for defective gas exchange with subsequent hypoxia and acidosis include: increased airway resistance by affecting chemoreceptors and baroreceptors, CB1 receptor stimulation inducing respiratory depression, and lastly damage to the bronchiolar epithelium and disruption of the alveolar surfactant (Herbst and Musgrave, 2020; Alon and Saint-Fleur, 2017).

Metabolic acidosis is considered the hallmark of methanol toxicity and our study was no different. Metabolic acidosis can be linked to accumulated formic acid. Formate, as an inhibitor of oxidative phosphorylation, leads to anaerobic metabolism and lactate elevation. Furthermore, metabolism of all alcohols results in an increased NADH/NAD + ratio, which favors the conversion of pyruvate to lactate in addition to hypotension and organ failure in severely poisoned patients can exacerbate elevated lactate concentrations (Doreen et al., 2020). Kaewput et al (2020) stated that respiratory failure is one of the most common end-organ failures in methanol toxicity and could be related to severe metabolic acidosis and hyperventilation.

In this study, although short ICU stay was noted in the majority of cases $(77 \%)$ and recovery was recorded in more than half of studied cases $(56.32 \%)$, total in-hospital mortality was $11.49 \%$ which substantially occurred during the first 24 hours. Comparably, recorded hospital morbidity was $10.34 \%$ and was statistically linked to ICU stay exceeding 24 hours. These findings stand in contrast to most previous studies considering acute intoxications: a diagnostic category usually associated with a relatively low mortality.

However, when evaluating the recorded high mortality and morbidity in the current study, it is important to clarify that the implicated substances are namely opioids (group I) and methanol (group III). Several studies pointed to the high mortality rates associated with opioids overdose with respiratory depression as the primary cause (Larochelle et al.,2018; 
Greene et al., 2019). Similarly, methanol toxicity is capable of producing end organ damage primarily due to formic acid formation (Ashurst and Nappe, 2019; Kaewput et al., 2020; Najari et al., 2020).

Additionally, the lack of difference in mean APACHE II score in both group I and III and their high values reflected the clinical severity, and the challenging nature of their management, which often demands timely, appropriate, effective diagnosis and treatment.

On the other hand, absence of recorded mortality in group II (cannabinoids) was not unexpected as other studies recorded that rapid improvement was the usual course although cases were critically ill at admission (Kourouni et al., 2020). These findings are also mirrored in lower mean APACHE II score among group II in comparison to other implicated substances.

In the current study, recording the highest mean SOFA score values among group II cases cannot be overlooked as such a score aim to trend overall organ dysfunction. This may provide more insight into the severity of cannabinoid abuse cases. Mortality in SCs users was recorded by Riederer et al. (2016) in a rate of $1.2 \%$. Documented major causes of death were cardiac arrest, respiratory depression, and acute kidney injury.

Unknown outcome was noted in $21.84 \%$ of cases due to against-medical-advice discharge, a high percentage highlighted by several studies. One explanation for increased risk of AMA discharge is the suboptimal management of withdrawal or cravings that can be a driving factor specially in substance use disorders which can have heterogeneous drug use patterns, and each of the use disorders needs explicit attention (Simon et al., 2019; Summers et al., 2018; Merchant et al., 2020).

\section{Conclusion}

Subgroup analysis of substance abuse-associated overdose admissions to the ICU revealed they were mainly related to opioids followed by cannabis or synthetic cannabinoids. Of the substance abuse admissions, patients were generally men, with short ICU stay and high total in-hospital mortality and morbidity. Disturbed level of consciousness was a common presentation among all types of substances. Admissions due to cannabinoids tend to improve with no recorded deaths. APACHE II can be employed for determination of severity in ICU patients with substance abuse, and SOFA score can point to the organ failure development.

\section{Recommendations}

Based on the previous data, special attention should be paid for describing the landscape of substance abuse and taking relevant actions given the frequent need to ICU care and resources in associated overdose cases. Given the rising costs of health care and the escalating abuse of opioids, prevention, rehabilitation, and treatment policies should be a seriously reevaluated and upgraded. Physicians should be aware with the continuous change of the illicit drug market. Severity Scores are at-hand tools that can be used in ICU for evaluation of patients with substance use disorders.
Taking into consideration the heterogeneity of substance abuse-associated overdose admissions to the ICU, further research is needed to address long-term chronic substance abuse as a special group, that may need a broader multidisciplinary approach. Moreover, qualitative studies are needed to explore reasons of AMA discharge which represent a clinical, ethical, and legal challenge.

\section{References}

Alon M. and Saint-Fleur M. (2017): Synthetic cannabinoid induced acute respiratory depression: Case series and literature review. Respiratory medicine case reports, 22:137-141.

Armstrong F, McCurdy MT, and Heavner MS (2019): Synthetic cannabinoid-associated multiple organ failure: case series and literature review. Pharmacotherapy: The Journal of Human Pharmacology and Drug Therapy, 39(4):508-13.

Ashurst JV, and Nappe TM (2019): Methanol Toxicity. In: StatPearls. StatPearls Publishing, Treasure Island (FL). Available on https://europepmc.org/ article/ NBK/ NBK482121

Bassiony MM, Abdelghani M, Salah El-Deen GM, et al., (2018) Opioid use disorders attributed to tramadol among Egyptian university students. Journal of addiction medicine,12(2):150-5.

Doreen B, Eyu P, Okethwangu D, et al., (2020): Fatal methanol poisoning caused by drinking adulterated locally distilled alcohol: Wakiso District, Uganda, June 2017. Journal of environmental and public health.1-6. Available on https://doi.org/10.1155/2020/5816162

General Secretariat of Mental Health and Addiction Treatment-Egypt, and Pompidou Group, Council of Europe, Med-SPAD: Results of the First Mediterranean School Survey Project on Alcohol and Other Drugs (MedSPAD) in Egypt (2017) available on https://www.coe.int/ en/ web/ pompidou/ mednet/medspad.

Greene JA, Deveau BJ, Dol JS, et al., (2019): Incidence of mortality due to rebound toxicity after 'treat and release'practices in prehospital opioid overdose care: a systematic review. Emergency Medicine Journal,36(4):219-24.

Gugelmann H, Gerona R, Li C, et al. (2014): 'Crazy Monkey'poisons man and dog: human and canine seizures due to PB-22, a novel synthetic cannabinoid. Clinical Toxicology,52(6):635-8.

Harris CR, and Brown A (2013): Synthetic cannabinoid intoxication: a case series and review. The Journal of emergency medicine, 44(2), 360-366.

Helander A., Bäckberg M., Hultén P, et al., (2014): Detection of new psychoactive substance use among emergency room patients: results from the Swedish STRIDA project. Forensic Science International.52: 618-624.

Herbst J, and Musgrave G (2020): Respiratory depression following an accidental overdose of a CBD-labeled product: A pediatric case report. Journal of the American Pharmacists Association, 60(1), 248-252. 
Hurst D. Loeffler G, and Mclay R (2011): Psychosis associated with synthetic cannabinoid agonists: a case series. Am J Psychiatry,168:1119.

Kaewput W, Thongprayoon C, Petnak, T, et al. (2020): Inpatient Burden and Mortality of Methanol Intoxication in the United States. The American Journal of the Medical Sciences.

Kerrigan S, and Goldberger BA (2020): Opioids. In Principles of Forensic Toxicology, Levine B and Kerrigan S (eds), Springer, Cham: p.p. 347369.

Kourouni I, Mourad B, Khouli H, et al., (2020): Critical Illness Secondary to Synthetic Cannabinoid Ingestion. JAMA Network Open, 3(7): e208516.

Lamy FR, Daniulaityte R, Nahhas RW, et al., (2017): Increases in synthetic cannabinoids-related harms: Results from a longitudinal web-based content analysis. International Journal of Drug Policy, 44:121-9.

Larochelle MR, Bernson D, Land T, et al., (2018): Medication for opioid use disorder after nonfatal opioid overdose and association with mortality: a cohort study. Annals of internal medicine,169(3):137-45.

Malekshahi T, Tioleco N, Ahmed N, et al., (2015): Misuse of atypical antipsychotics in conjunction with alcohol and other drugs of abuse. Journal of substance abuse treatment,48(1):8-12.

Martins SS, Sampson L, Cerdá M, et al., (2015): Worldwide prevalence and trends in unintentional drug overdose: a systematic review of the literature. American journal of public health, 105(11), e29-e49.

McLarnon ME, Monaghan TL, Stewart SH, et al., (2011): Drug misuse and diversion in adults prescribed anxiolytics and sedatives. Pharmacotherapy, 31(3), 262-272.

Merchant E, Burke D, Shaw L, et al., (2020): Hospitalization outcomes of people who use drugs: One size does not fit all. Journal of Substance Abuse Treatment,112:23-8.

Mohamed NR, El Hamrawy LG, Shalaby AS, et al., (2015): An epidemiological study of tramadol $\mathrm{HCl}$ dependence in an outpatient addiction clinic at Heliopolis Psychiatric Hospital. Menoufia Medical Journal, 28(2):591.

Montandon G, and Horner RL (2019): Electrocortical changes associating sedation and respiratory depression by the opioid analgesic fentanyl. Scientific reports, 9(1):1-1.

Mowry JB, Spyker DA, Brooks DE, et al., (2016): 2015 Annual Report of the American Association of Poison Control Centers' National Poison Data System (NPDS): 33rd Annual Report. Clinical Toxicology, 54(10), 924-1109.

Najari F, Baradaran I, and Najari D (2020): Methanol Poisoning and Its Treatment. International Journal of Medical Toxicology and Forensic Medicine, 10(1), 26639.

Nakhaee S, Amirabadizadeh A, Brent J, et al., (2019): Tramadol and the occurrence of seizures: a systematic review and meta-analysis. Critical reviews in toxicology,49(8):710-23.

Nelson LS and Olsen D (2019): Opioids. In Goldfrank's Toxicologic Emergencies, Nelson L.S. et al. (eds), 11th edition, McGraw-Hill, New York, Chapter 36:519-537

Orsini J, Din N, Elahi E, et al., (2017): Clinical and epidemiological characteristics of patients with acute drug intoxication admitted to ICU/Journal of Community Hospital Internal Medicine Perspectives, 7:4, 202-207

Rapsang AG, and Shyam DC (2014): Scoring systems in the intensive care unit: a compendium. Indian journal of critical care medicine: peer-reviewed, official publication of Indian Society of Critical Care Medicine,18(4):220.

Riederer AM, Campleman SL, Carlson RG, et al., (2016): Acute poisonings from synthetic cannabinoids - 50 US Toxicology Investigators Consortium registry sites, 2010-2015. MMWR. Morbidity and mortality weekly report, 65(27): 692.

Sabry N, Abdel Maksoud M, Sedrak A, et al., (2015): National Research for Addiction, Final Report, Research Unit- General Secretariat of Mental Health and Treatment of Addiction.

S Abou El Magd, MA Khalil, SM Gohar, et al., (2018): Tramadol misuse and dependence in Egypt and the UAE: user characteristics and drug-use patterns", International Addiction Review, 2(1): pp 6-13.

Sekulic AD, Trpkovic SV, Pavlovic AP, et al., (2015) Scoring systems in assessing survival of critically ill ICU patients. Medical science monitor: international medical journal of experimental and clinical research,21:2621.

Simon R, Snow R, and Wakeman S (2019): Understanding why patients with substance use disorders leave the hospital against medical advice: a qualitative study. Substance Abuse, 18:1-7.

Stevens J P, Wall M J, Novack L, et al., (2017): The critical care crisis of opioid overdoses in the United States. Annals of the American Thoracic Society, 14(12), 1803-1809.

Summers PJ, Hellman JL, MacLean MR, et al., (2018): Negative experiences of pain and withdrawal create barriers to abscess care for people who inject heroin. A mixed methods analysis. Drug and alcohol dependence,190:200-8.

Sunshine I, Appleton H D, \& Dubowski K (1961): Alcohol in biological materials. In Standard Methods of Clinical Chemistry, Elsevier, Vol. 3 :pp. 1-13.

Takematsu M, Hoffman RS, Nelson LS, et al., (2014): A case of acute cerebral ischemia following inhalation of a synthetic cannabinoid. Clinical Toxicology,52(9):973-5.

Taskinen M R, Söderlund S, Bogl L H, et al., (2017): Adverse effects of fructose on cardiometabolic risk factors and hepatic lipid metabolism in subjects with abdominal obesity. Journal of internal medicine, 282(2), 187-201. 
Tournebize J, Gibaja V, and Kahn J P (2017): Acute effects of synthetic cannabinoids: Update 2015. Substance Abuse, 38(3), 344-366.

World Drug Report (2018): by the United Nations Office on Drugs and Crime (UNODC) available at https://www.unodc.org/wdr2018/index.html
World Drug Report (2019): by the United Nations Office on Drugs and Crime (UNODC) available at https://wdr.unodc.org/wdr2019/

World Drug Report (2020): by the United Nations Office on Drugs and Crime (UNODC) available at https://wdr.unodc.org/wdr2020/en/drug-usehealth.html

\title{
تقييم حالات سوء استخدام المواد المخدة الذين ادخلوا الرعاية المركزة بمركز السموم بمستشفيات جامعة عين شمس من خلال أنظمة تقييم سريرية التحة محددة
}

\author{
رغدة عصام الدين، و هدى صلاح عثمان، و هدى محمد صلاح الدين' \\ الملخص العربى
}

الهـف: تهدف الدر اسـة الحاليـة إلى تقيم الخصـائص السريرية للحالات المتعلقة بتعاطي المخدرات وفائدة مجموع نقاط مقياس الاباتشى الثانى ومقياس تقييم الفنشل العضوي المتتابع (صوفا) كمتنبئين للشدة والنتيجة بين تلك الحالات.

الطريقـة: الدر اسـة مستعرضـة قائمــة على الملاحظـة في المستشـفى أجريت على المرضـى الذين يتعـاطوا المخدر ات، مـن كـلا الجنسين، و الذين تم دخولهم في وحدة الرعاية المركزة بمركز علاج السموم في مستشفيات جامعة عين شمس في الفترة من الأول

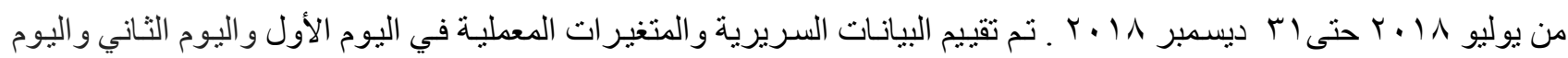
الر ابع و اليوم السادس ونقطة النهاية و استخدمت في حساب درجات مقياس الاباتثى الثانى ومقياس تقييم الفثل العضوي المتتابع النتائج: تم تسجيل ما مجمو عه NV حالة متعلقة بتعاطي المخدرات في وحدة العناية المركزةو تم تقسيم الحالات إلى المجموعـة الأولى (تر امادول و / و المو اد الأفيونية) ، و المجموعة الثانية (القنب أو القنب الصناعي) و المجموعة الثالثة (حالات إيثانول تتطوي

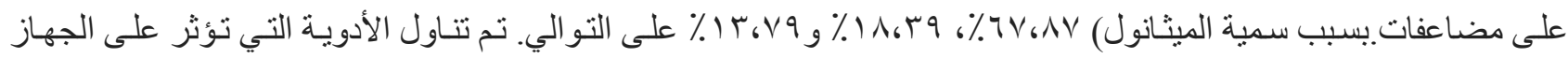

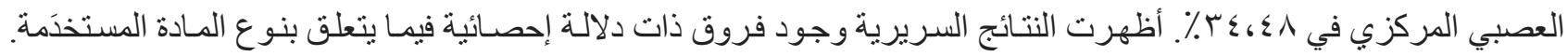
تختلف درجات مقياس الاباتثى الثانى ومقياس تقييم الفشل العضوي المتتابع فى المجمو عات الثلاث. ولوحظ بقاء قصير في وحدة

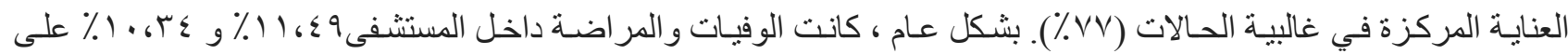
التو الي. كان معدل الاعتلال أعلى بين حالات الإقامة الطويلة في وحدة العناية المركزة بينما تم تسجيل الوفيات في الغالب خلال الـ

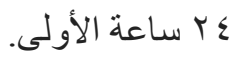

الخلاصة: يمكن استخدام نتائج مقياس الاباتشى الثانى ومقياس تقييم الفشل العضوي المتتابع في قياس الثدة للدى مرضى وحدة

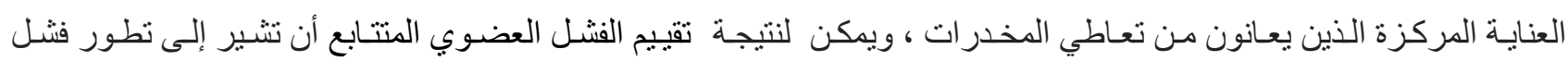
الأعضاء. 